\section{Brain, Behavior and Evolution}

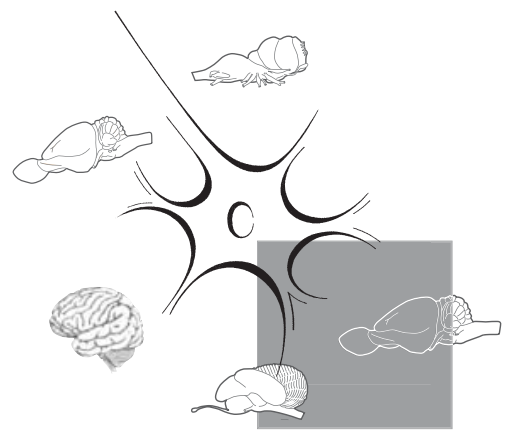

As all the readers of Brain, Behavior and Evolution are undoubtedly aware, 2009 was awash with celebrations of Darwin's bicentenary and the 150th anniversary of the publication of On the Origin of Species. As part of their contribution to these celebrations, Biology Letters published three special features on topics relating to evolution, including one on brain evolution, which was published in February 2009 (vol. 5, issue 1). As the guest editor of this feature, I regarded it as an opportunity to showcase our field of study to the wider biological sciences community.

The study of brain evolution is of course a wide and diverse endeavor, from describing and elucidating the patterns of descent with modification over time to thinking about the selective pressures that have shaped nervous systems. Kosik [2009] and Reichert [2009] briefly review the evolution and conservation of the mechanisms involved in synaptic transmission and in brain development, respectively, across many different groups of animals. The findings coming out of this fascinating work elucidate how complicated (molecular) structures and complexes can evolve from simpler ones, because the same molecules can often perform different functions in different contexts. This provides conceptual answers to the kinds of questions raised by Darwin himself about how complex structures like a vertebrate eye could ever have evolved from simpler ancestral structures. In an article associated with (but not in) the special feature, Strausfeld [2009] explores phylogenetic patterns in nervous systems, in this case using them to test hypotheses about the origins of insects.
Highlights and Perspectives on Evolutionary Neuroscience

Published online: March 8, 2010

\title{
Darwin Celebrations Highlight Brain Evolution
}

\author{
Tom V. Smulders \\ Centre for Behaviour and Evolution, Institute of Neuroscience, Newcastle University, \\ Newcastle upon Tyne, UK
}

Understanding patterns of brain evolution also shows us that different lineages have evolved different structural solutions to similar functional problems. Ito and Yamamoto [2009] and Reiner [2009] take us through the forebrains of fishes and birds, respectively, and compare their organization to that of the well-studied mammalian forebrain. Comparative studies of this type may allow us in the future to better understand structure-function relationships between brain and behavior [Smulders, 2009]. The same approach is taken by Amrein and Lipp [2009] to explore the importance of adult neurogenesis in different mammalian species. On the other end of the spectrum, Sol [2009] and Isler and Van Schaik [2009] explore their ideas about the pressures driving the evolution of brain size in birds and mammals, relating them to the possible cognitive advantages on the one hand, and to the constraints of developing large brains on the other hand. And it is of course impossible to understand such constraints without knowing the mechanisms through which developmental processes cause differences in brain size. Striedter and Charvet [2009] compare birds and mammals that have independently evolved large brains, and find similar changes in the proliferative zones of their brains.

There are of course many other aspects of brain evolution that are being studied at present. The special feature in Biology Letters was only meant to provide an introduction to this fascinating topic for people who are not familiar with the material. The importance of understanding brain evolution for anyone working in neuroscience cannot be understated [Smulders,
2009]. Hopefully, efforts like the special feature will increase the general interest in brain evolution and awareness of its implications for understanding brains. I encourage all readers of Brain, Behavior and Evolution to help with this advocacy.

\section{References}

Amrein I, Lipp HP (2009): Adult hippocampal neurogenesis of mammals: evolution and life history. Biol Lett 5:141-144.

Isler K, Van Schaik CP (2009): Why are there so few smart mammals (but so many smart birds)? Biol Lett 5:125-129.

Ito H, Yamamoto N (2009): Non-laminar cerebral cortex in teleost fishes? Biol Lett 5:117121.

Kosik KS (2009): Exploring the early origins of the synapse by comparative genomics. Biol Lett 5:108-111.

Reichert H (2009): Evolutionary conservation of mechanisms for neural regionalization, proliferation and interconnection in brain development. Biol Lett 5:112-116.

Reiner A (2009): Avian evolution: from Darwin's finches to a new way of thinking about avian forebrain organization and behavioural capabilities. Biol Lett 5:122-124.

Smulders TV (2009): The relevance of brain evolution for the biomedical sciences. Biology Letters 5:138-140.

Sol D (2009): Revisiting the cognitive buffer hypothesis for the evolution of large brains. Biol Lett 5:130-133.

Strausfeld NJ (2009): Brain organization and the origin of insects: an assessment. Proc Biol Sci 276:1929-1937.

Striedter GF, Charvet CJ (2009): Telencephalon enlargement by the convergent evolution of expanded subventricular zones. Biol Lett 5: 134-137.

\section{KARGER}

Fax +4161306 1234 E-Mail karger@karger.ch www.karger.com
(C) 2010 S. Karger AG, Base 0006-8977/10/0751-0008\$26.00/0

Accessible online at: www.karger.com/bbe
Tom V. Smulders

Centre for Behaviour and Evolution, Institute of Neuroscience

Henry Wellcome Building for Neuroecology, Framlington Place

Newcastle University, Newcastle upon Tyne NE2 4HH (UK)

Tel. +44 191222 5790,Fax +44 191222 5622,E-Mail tom.smulders@ncl.ac.uk 